\title{
Evaluation of the Effect of Fracture Geometry on Permeability Based on Laboratory Study and Numerical Modelling
}

Rudarsko-geološko-naftni zbornik

(The Mining-Geology-Petroleum Engineering Bulletin) UDC: 622:1

DOI: 10.17794/rgn.2021.5.14

Original scientific paper

\author{
Mohammad Faez'; Ahmad Ramezanzadeh'; Reza Ghavami-Riabi'; Behzad Tokhmechi' \\ ${ }^{1}$ Department of Mining Eng., Petroleum and Geophysics, Shahrood University of Technology, 7 Tir Square, Shahrood, Iran
}

\begin{abstract}
The geometry of fractures includes orientation, spacing, aperture, and are among the parameters affecting permeability in rocks. Studying the effect of fracture geometry on permeability in a laboratory scale requires the selection of a suitable sample in terms of physical and mechanical properties. Therefore, in this study, fibrous fiber was selected due to low water absorption and permeability, as well as its non-brittle behavior and flexibility. In order to investigate the effect of fracture geometry on permeability, 1, 2, 3, and 4 fractures with spacing greater than $50 \mathrm{~mm}, 50 \mathrm{~mm}, 25 \mathrm{~mm}$, and $15 \mathrm{~mm}$ and with orientations of $0,15,30,45$, and 60 degrees to the horizon in the sample were created. The fractures did not come into contact with the surface of the sample. The results showed that the permeability increases exponentially with increasing orientation and a decrease in the spacing. This situation is mostly seen in fractures with orientations larger than 30 degrees. Also, the permeability measured in the laboratory was compared with the results obtained from the numerical method of distinct elements and UDEC software. The results showed an error of about $10-15 \%$, which is wellmatched between the permeability obtained from the laboratory and the numerical method.
\end{abstract}

Keywords:

permeability; fracture geometry; fibrous fiber; distinct element; UDEC software

\section{Introduction}

The orientation and linear frequency of fractures are often the fundamental parameters required in rock engineering (Zheng et al., 2018; Zheng et al., 2019), and they are able to be simply and practically measured. Subsurface fractures are able to cause a high-permeability fluid-flow route along rock formations. Hence, researchers have investigated various studies to perceive the mechanisms of flow along fractured formations to exploit subsurface energy, such as geothermal and oil reservoirs (Tsang, 1984; Gong and Rossen, 2018; Zimmerman, 1996; Crandall et al., 2010; Wang and Yu, 2019). Generally, these studies concluded that many fracture characteristics influence the conductivity of fractured rocks. Relevant properties consist of density, spacing, orientation, length, aperture, porosity, roughness, and network connectivity. Above all, aperture and porosity are especially significant and rely on stress state. There is a novel method for determining the permeability tensor of fracture rock masses. The proposed analytical approach is developed based on the orientation and linear frequency of fractures, along with a value of the permeability in any direction (Zheng et al., 2020). There is a new fracture permeability model according to

Corresponding author: Mohammad Faez mp.faez@gmail.com surrounding rocks and matrix pressure. The results demonstrated that the lower the initial fracture porosity, matrix modulus, shear modulus ratio between the reservoir and neighboring rocks, Poisson's ratio of the reservoir and the shape factor of the reservoir, the greater the stress-dependency of fracture permeability thorough the hydrocarbon production (Yu et al., 2020). The relation between the joint roughness coe-cient and the permeability of a fracture is considered. The joint surface was created by the Joint Roughness Coefficient (JRC) and fractal dimension. The results showed that aperture size has a remarkable impact on permeability (Rezaei Niya and Selvadurai, 2019). Fracture orientation and fluid flow direction recognition in carbonates using diffusionweighted and nuclear magnetic resonance imaging, are studied (Fheed et al., 2020). The influence of the roughness parameter on steam and the formation of eddy in fractures of rock according to the numerical approach have been researched. The results demonstrated that the rise in sophisticated stream property, for example eddies arising next to the surface of fracture was straightly concerned with the change in roughness (Briggs et al., 2016). The impact of stress-dependent fracture permeability measurements on shale gas production is inquired. The results expressed that stress-induced fracture closure was able to cause striking loss of cumulative gas production ( $\mathbf{L i}$ et al., 2021). The influence of in-situ stresses and fracture geometry on hydraulic aperture and 
permeability in broken tanks is studied. The combination of the finite element method and Discrete Fracture Network (DFN) to model the broken reservoir are used. The results demonstrated that the aperture and permeability were highly affected by the difference between the angle of the fracture length and the direction of the principle stress. The aperture has the highest value for an angle of 15 degrees because in this case, the fracture will experience the lowest shear stress (Bisdom et al., 2016). The role of inter-well fracture geometry in permeability in low-deformability carbonate rocks is investigated. Surveys and modelling based on distinct fracture networks and data extracted from outcrops at different distances from each other showed that the slightest change in the geometry and topography of the area would lead to a change in permeability. In the past, conductivitybased analyses, such as intrusion probability, have not been able to detect permeability changes (Bisdom et al., 2017). The effect of discontinuous geometry on nonDarcy flow under confinement pressure is examined. Four samples of sandstone with different sizes are used. The findings expressed that the equation of Forchheimer along with both parameters $\mathrm{A}$ and $\mathrm{B}$, which features the non-Darcy flow in fractures, possesses a great tendency to the geometry of a fracture. While the confining pressure increases, the coefficients of the equation increase continuously due to the reduction of the opening and the inhomogeneous distribution of the cavities (Chen et al., 2019). The permeability of crushed coal, considering the role of discontinuity geometry and water content is assessed. Three types of fractures in the coal seam have been investigated: several small fractures, one longitudinal fracture, and one radial fracture. The results showed that fracture geometry not only changes the magnitude of permeability but also has a significant effect on controlling water absorption, swelling strain, and permeability evaluation (Wang et al., 2011). A laboratory study of the permeability response in fractured rocks under the influence of both hydraulic-mechanical couples and discontinuity geometry was conducted. Samples of sandstone and limestone were used for the experiment. The test results showed that the permeability of sandstone samples with two discontinuities is three times higher than the permeability of sandstone samples with one discontinuity. However, permeability is the same for limestone samples without discontinuity and several discontinuities (Zhang et al., 2020). The numerical modelling to evaluate the permeability of rocks with several fractures is used. The modelling is based on a distinct fracture network and dual porosity. The results showed that distinct fractures and the intersection of fractures have a significant effect on the local flow rate, which depends on the location of the fractures (Yao et al., 2015). The models based on crack propagation and bending and its effect on stress-dependent permeability are developed. This modelling is a combination of the finite element and distinct element methods. Thus, the displacement of the fracture wall and changes in the aperture can be modelled. The results showed that fractures that are prone to accept shear stress play an important role in increasing fluid flow in the fracture. Since shear stress can increase the amount of volume and consequently the amount of aperture (Latham et al., 2013). The relationship between maximum permeability direction and average principal stress in fractured rocks is analyzed. The results showed that in the case that shear displacement induces a heterogeneous transfer of fractures, the maximum permeability is likely to be in the direction of moderate principal stress (Lang et al., 2018). A numerical method to investigate permeability changes due to effective confining stresses in limestone is used. The results showed that in the direction of greater stress, permeability is higher than the other directions of stress (Arianfar and Ramezanzadeh., 2020). There is the study about two-component fluid front tracking in a fault zone and discontinuity with permeability heterogeneity. The results showed that a fracture between the two porous mediums remarkably affects the fluid flow, and the sweep effectiveness reduces as the flow rate rises (Shiri and Hassani, 2021). Laboratory studies are limited in terms of the effect of fractures on permeability due to sample preparation problems. Also, studies illustrated that the discontinuity geometry has not had a significant effect on permeability in a laboratory. In this research, an attempt has been made to investigate the effect of fracture geometry on permeability by selecting the appropriate sample in terms of physical and mechanical properties. For this purpose, a synthetic sample of fibrous fiber was used based on their physical and mechanical properties. The aim of selecting the synthetic sample is that the fracture orientation and spacing are merely considered and other parameters, such as aperture and porosity of the sample, remain the same. Therefore, the synthetic sample better meets these conditions because the rock material samples are more vulnerable and during the cutting of the samples, micro-cracks are more likely to be created. Then, permeability was investigated by creating fractures with different spacing and orientations. Finally, the results were compared with the numerical method according to the distinct element method and using UDEC software.

\section{Materials and methodology}

Selecting the appropriate specimen to inquire the impact of fracture geometry on permeability is one of the most important sections in this research. Concrete materials are not a suitable option for this purpose due to their brittle behavior, high water absorption and porosity. Therefore, another artificial material known as fibrous fiber specimen was used (see Figure 1). These samples are created at a pressure of $2000 \mathrm{~kg} / \mathrm{cm}^{2}$ and high temperature and cut into cylinders with a diameter of $38 \mathrm{~mm}$ and a length of $100 \mathrm{~mm}$ using a $\mathrm{CNC}$ machine. The $\mathrm{P}$ and S-wave velocities were measured by a PUNDIT $\mathrm{lab}+$ device with two converters (a transmitter and a re- 
ceiver). A frequency of $500 \mathrm{kHz}$ was used to measure the compressive wave and $250 \mathrm{kHz}$ for shear wave velocity. Furthermore, a uniaxial compressive strength test was conducted by a servo control machine with a capacity of

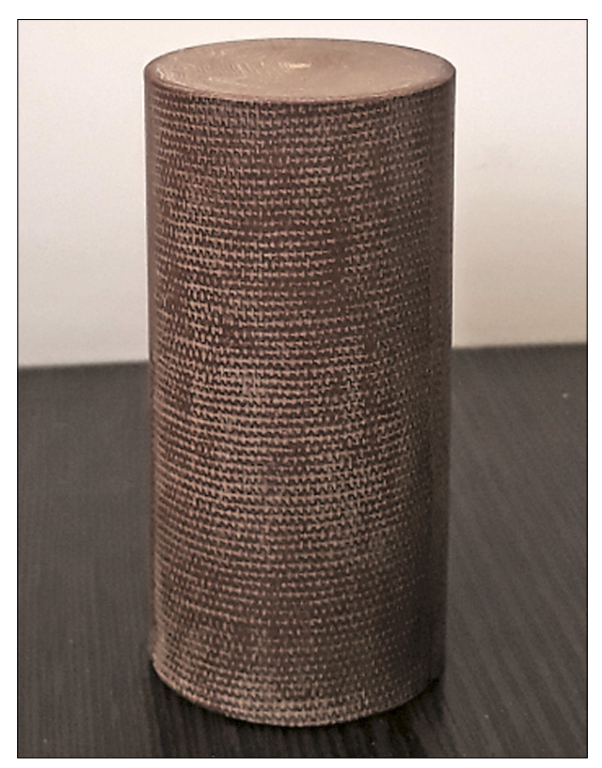

Figure 1: Fibrous fiber specimen
60 tons and a loading rate of $0.1 \mathrm{~mm} / \mathrm{min}$. The stressstrain behavior of the fibrous fiber sample is linear up to nearly $60 \mathrm{MPa}$. This sample expressed a plastic and nonlinear behavior for stress higher than $60 \mathrm{MPa}$ until the moment of rupture of the sample (see Figure 2). The ductile property of specimens is useful for creating fractures with different orientation and spacing. Cutting brittle materials results in unwanted cracks in specimens. Hence, the fibrous fiber specimen was chosen as an appropriate sample because of its low water absorption, porosity, the flexible behavior of specimen and the low permeability, which will be discussed later. The physical and mechanical properties of the specimen are shown in Table 1.

\subsection{Permeability coefficient}

The permeability coefficient of the sample is another parameter in the study of fracture geometry on permeability. In order to measure the permeability coefficient of fibrous fiber samples, a permeability measuring device was designed in Shahroud University of Technology at the Faculty of Mining Engineering (see Figure 3). Also, the components of the device including 1: Injection fluid, 2: Suction pipe, 3: Injection pump, 4: Valve, 5: Fluid

Table 1: Physical and mechanical properties of fibrous fiber specimen

\begin{tabular}{|l|l|l|l|l|l|l|}
\hline $\begin{array}{l}\text { Density } \\
\left(\mathbf{g} / \mathbf{c m}^{\mathbf{3}}\right)\end{array}$ & $\begin{array}{l}\text { Porosity } \\
(\mathbf{\%})\end{array}$ & $\begin{array}{l}\text { Water Absorption } \\
\mathbf{( \% )}\end{array}$ & $\begin{array}{l}\text { P-velocity } \\
(\mathbf{m} / \mathbf{s e c})\end{array}$ & $\begin{array}{l}\text { S-Velocity } \\
(\mathbf{m} / \mathbf{s e c})\end{array}$ & $\begin{array}{l}\text { UCS } \\
(\mathbf{M P a})\end{array}$ & $\begin{array}{l}\text { Permeability } \\
(\mathbf{m} / \mathbf{s e c})\end{array}$ \\
\hline 1.35 & insignificant & insignificant & 3419 & 1429 & 127 & $7.7210^{-10}$ \\
\hline
\end{tabular}

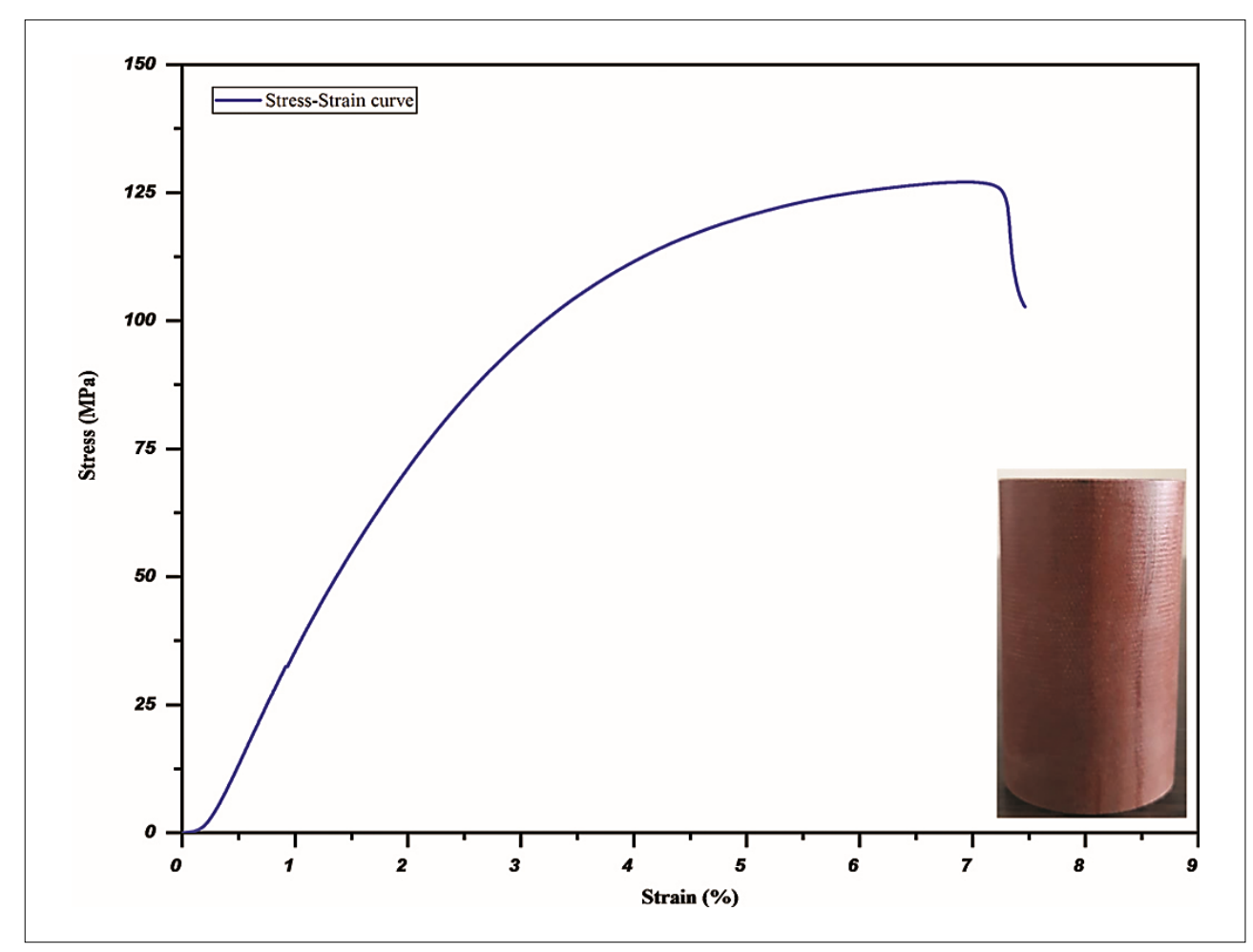

Figure 2: Stress-strain curve related to fibrous fiber specimen 
behind accumulator piston, 6: Piston, 7, 8 and 9: any fluid intended for injection, 10 and 11 Injection path, 12: bypass valve, 13: core chamber, 14: core, 15: barometer, 16: oil tank, 17: oven, 18: outlet chamber, 19: nitrogen gas for back pressure are shown in detail in Figure 4. The device can be used to measure the permeability of cores with 25 and $38 \mathrm{~mm}$ in diameter. Other features of this device include measuring absolute and relative permeability along with other important parameters, such as oil and residual water saturation, flow rate and pressure. Based on the measurements obtained by this device, the permeability coefficient was measured for fibrous samples of $7.72 \mathrm{E}-10 \mathrm{~m} / \mathrm{s}$. Therefore, due to the very low permeability coefficient, the fibrous fiber sample can be selected as a suitable sample to investigate the effect of fracture geometry on permeability.

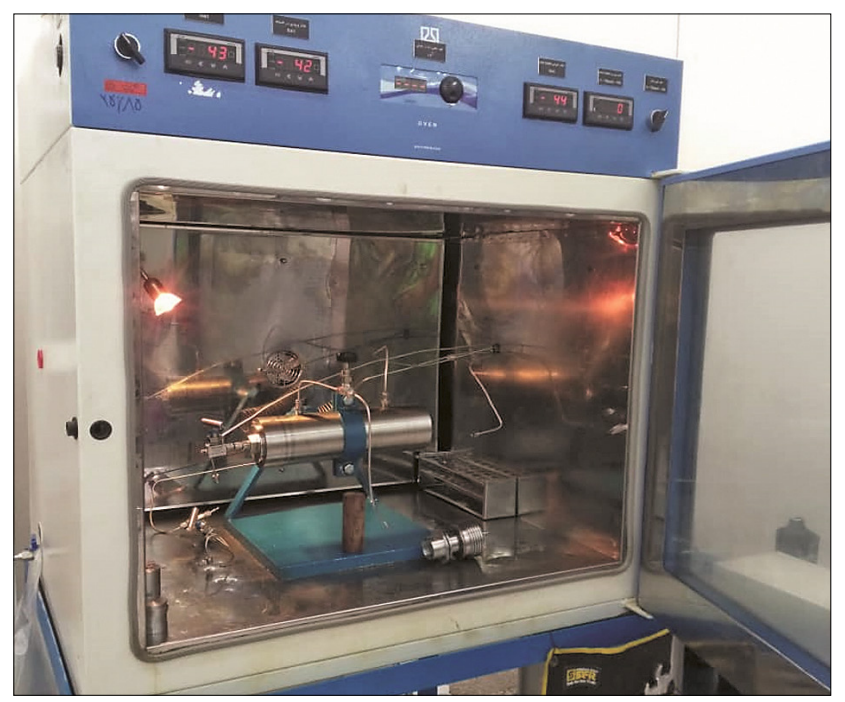

Figure 3: Overview of the permeability measuring device at the Faulty of Mining Engineering in Shahrood University of Technology

\section{Laboratory study of the effect of fracture geometry on permeability}

\subsection{Development of model}

In order to investigate the effect of fracture geometry on permeability, discontinuities with angles of $0,15,30$, 45 , and 60 degrees were selected. Also, fractures with different spacing were created on the sample using a CNC machine in such a way that the fractures did not cut the surface of the sample. Therefore, in samples with the orientation of 0,15 , and 30 degrees included 1, 2, 3, and 4 fractures with spacing greater than $50 \mathrm{~mm}, 50 \mathrm{~mm}, 25$ $\mathrm{mm}$, and $15 \mathrm{~mm}$, respectively, in samples with the orientation of 45 degrees 1, 2, and 3 fractures were created with spacing greater than $50 \mathrm{~mm}, 30 \mathrm{~mm}$, and $15 \mathrm{~mm}$, and in samples with $60^{\circ}$ orientation, 1 and 2 fractures with spacing greater than $50 \mathrm{~mm}$ and $12 \mathrm{~mm}$ were created, respectively. A total of 17 cases were considered to investigate the effect of fracture geometry on permeability (see Figures 5,9 ). In all samples, the amount of fracture aperture is the same. Therefore, orientations and spacing will be the only major factor affecting permeability.

\subsection{Simple regression}

Before developing linear multivariate relationships, it is necessary to examine the relationship between each of the input parameters and the output parameters. For this purpose, 4 common forms of simple regression, namely linear, logarithmic, exponential, and power were used and the relationship was examined. The results showed that both input parameters (orientations and number of fracture) had a significant relationship with the output parameter (permeability). Hence, both of them can be used in the next steps to develop multivariate relationships. Also, the most appropriate relationship between

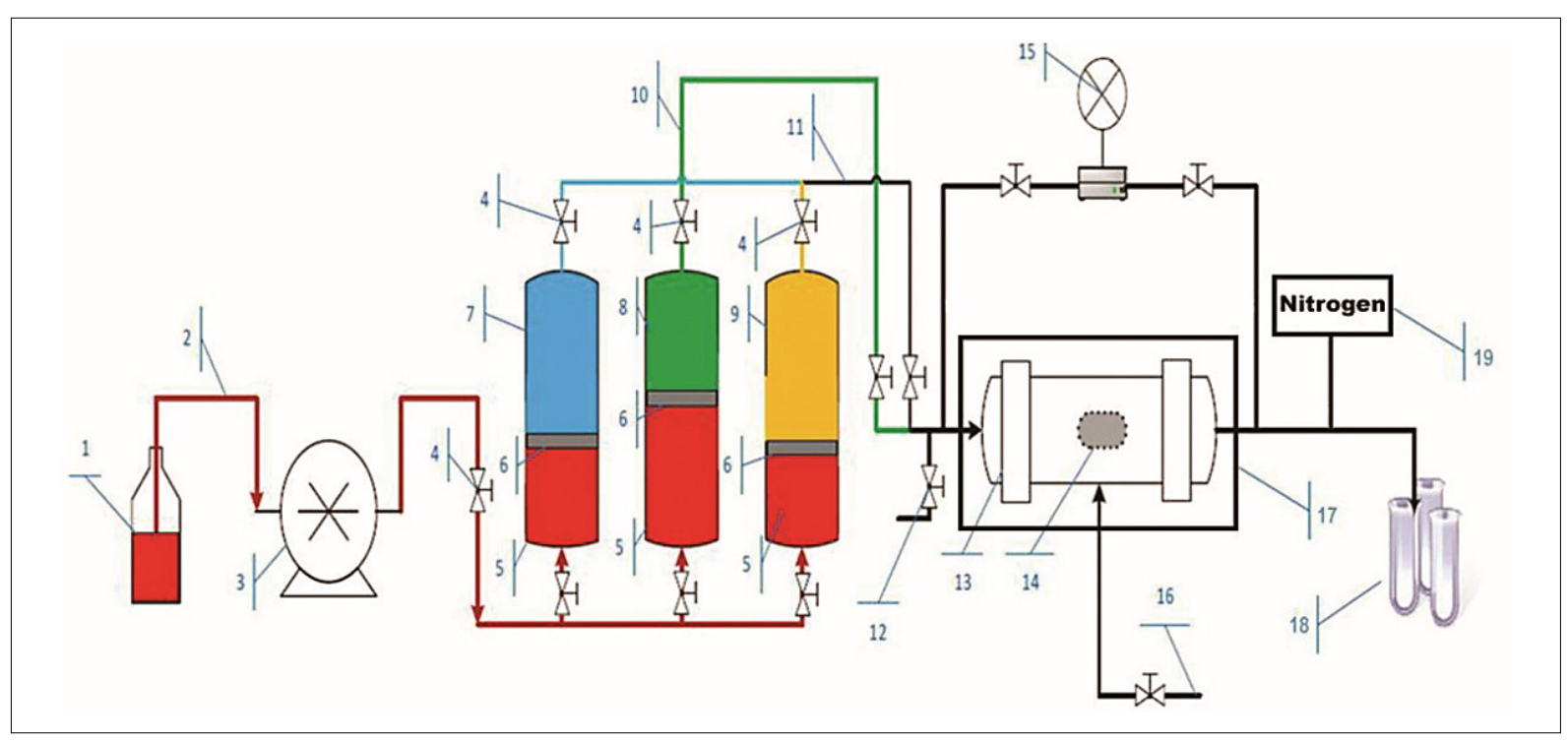

Figure 4: Components of the permeability device. (Arianfar and Ramezanzadeh., 2020) 


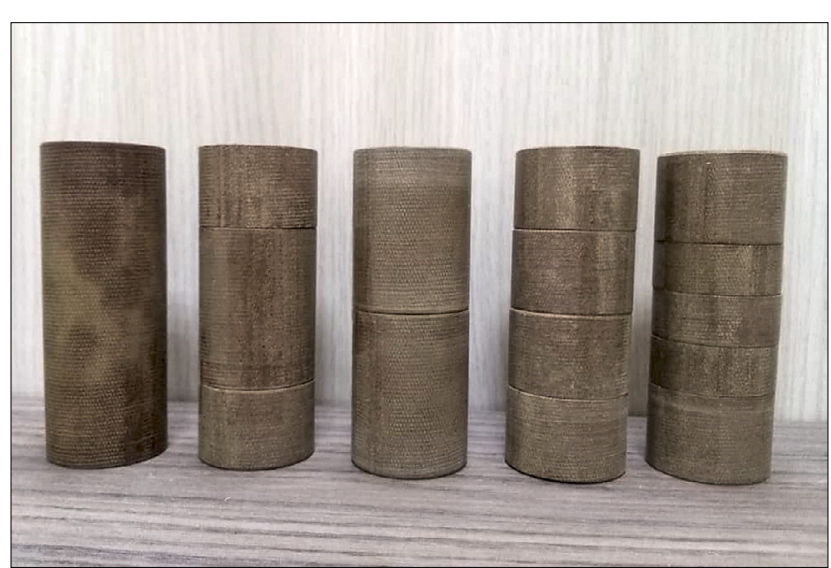

Figure 5: Geometry of discontinuities for zero degree orientation

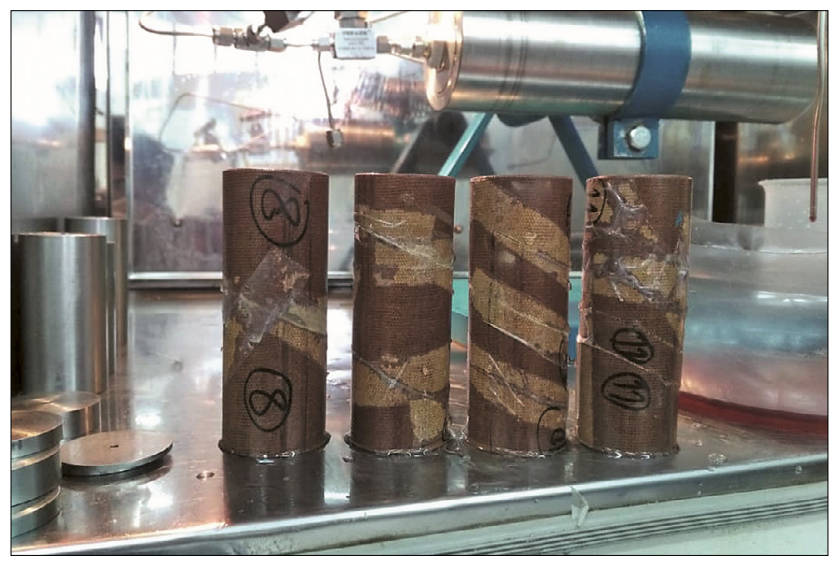

Figure 6: Geometry of discontinuities for 15 degree orientation

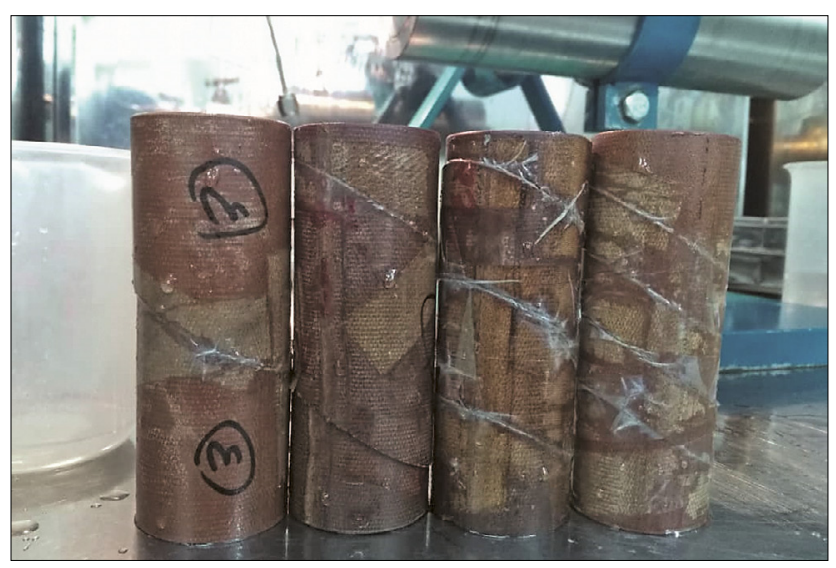

Figure 7: Geometry of discontinuities for 30 degree orientation

the orientation of fractures and permeability is exponential with a coefficient of determination between 0.90 0.95 . This relationship is direct, i.e. with an increase in the number of fractures or a decrease in the spacing, the permeability of the rock increases dramatically, especially for fractures greater than 30 degrees (see Figure 10). It seems that the difference between hydraulic gra-

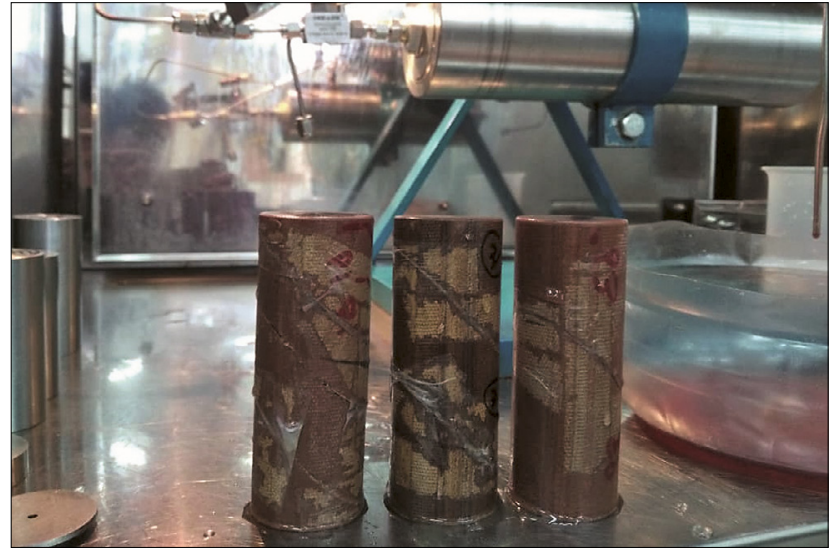

Figure 8: Geometry of discontinuities for 45 degree orientation

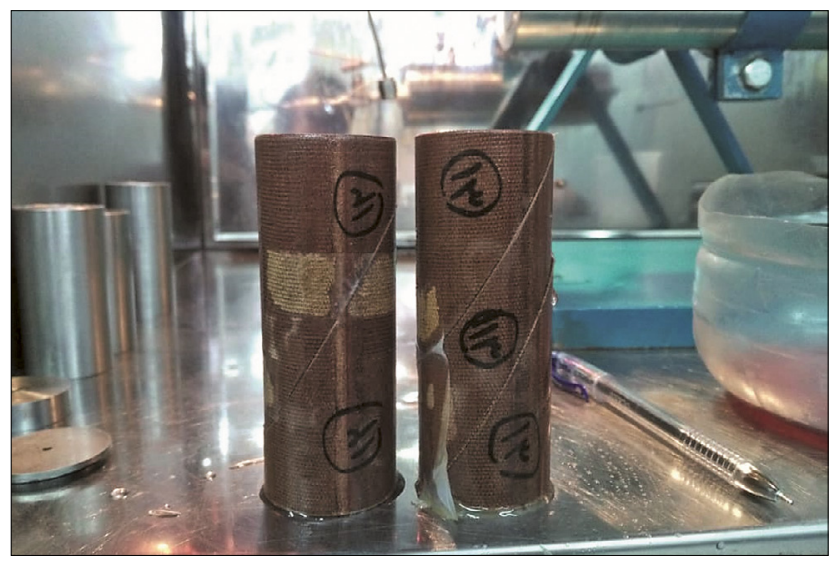

Figure 9: Geometry of discontinuities for 60 degree orientation

dient through fractures plays a key role in increasing permeability for steep fractures. Also, the most appropriate relationship between the number of fractures and permeability is linear with a coefficient of determination between $0.99-1$. The relationship is also direct and its trend was illustrated in Figure 11. The test results demonstrated that if the number of fractures is increased or the spacing is decreased, the permeability rate will decrease and the fractures do not affect permeability. This conclusion is much more apparent for fractures with smooth orientation and it is predicted that the same effect appears in other orientations providing that the number of fractures rises.

\subsubsection{Linear multivariate regression analysis}

In linear multivariate regression, the relationship between the input parameters of the independent variables and the output parameter of the dependent variable is presented as follows in Equation 1:

$$
Y=\beta 0+\beta 1 X 1+\cdots+B n X n
$$

In this regard, $X 1, X n$, are independent variables,

$\beta 0, \beta 1, \ldots, B n$ are the regression coefficients of the independent variables and $\mathrm{Y}$ is the dependent variable. 


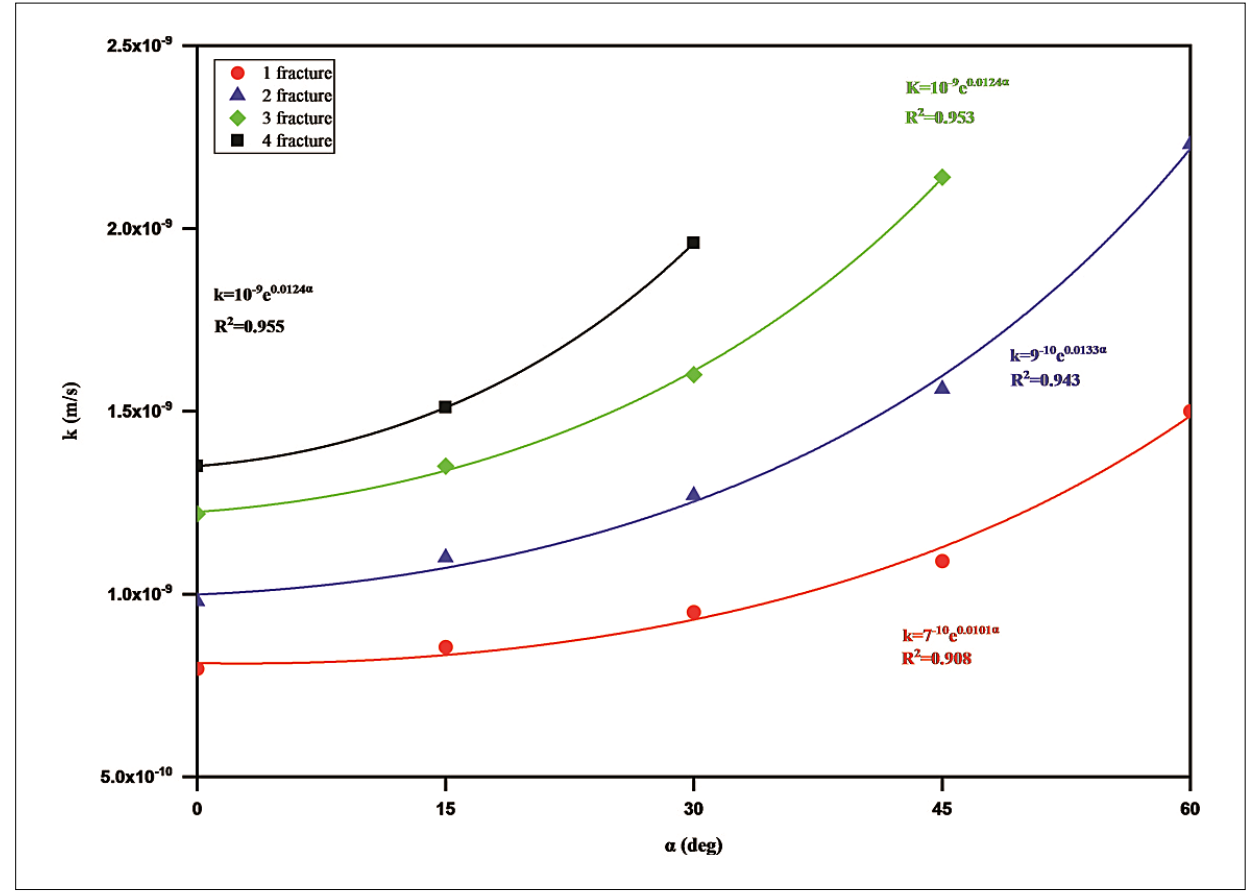

Figure 10: Permeability against fracture orientation and number of fractures

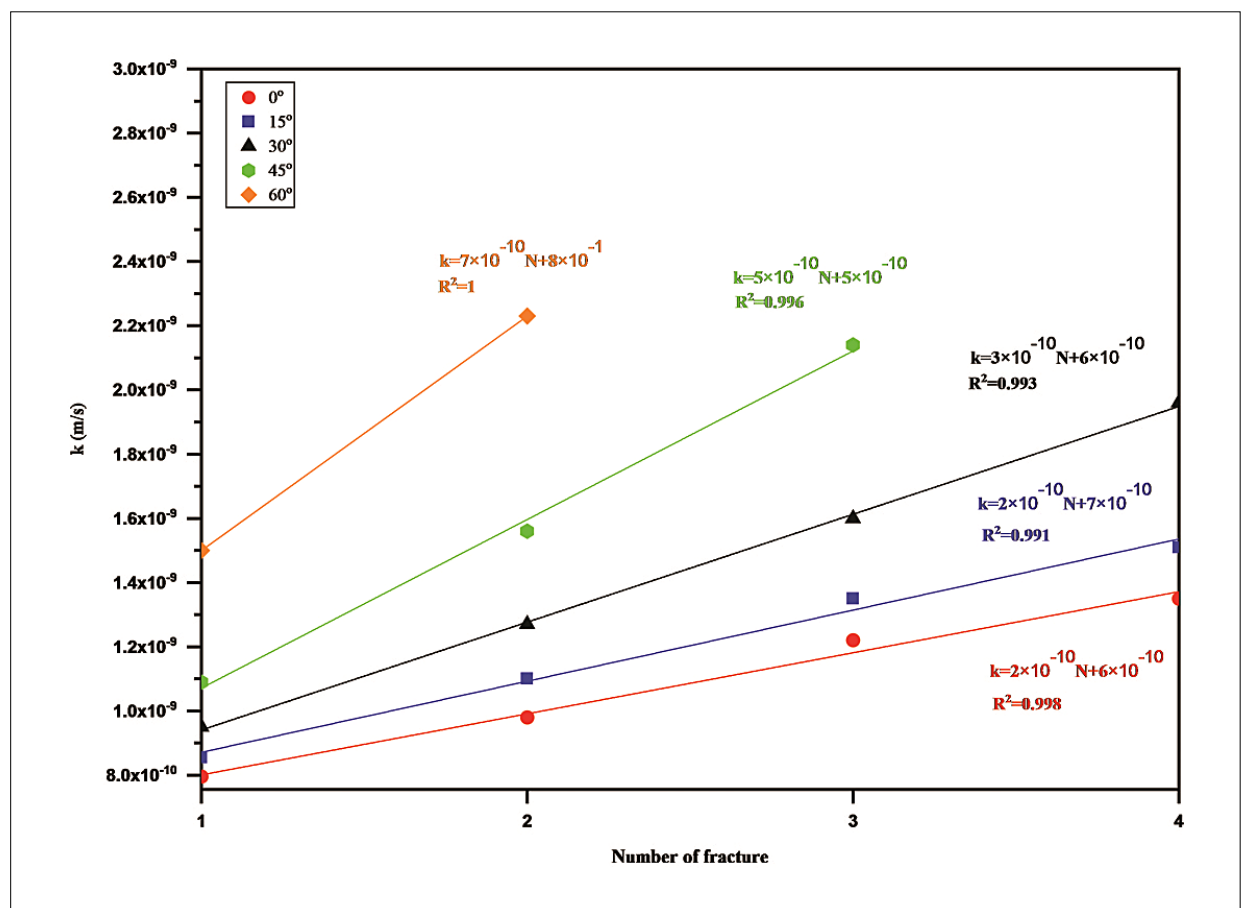

Figure 11: Permeability against the number of fractures and orientation of fractures

By entering the training data into SPSS software and performing multivariate regression analysis, regression coefficients can be determined. In this analysis, permeability was considered as a dependent parameter and the number of fractures and the orientation of fractures were considered as independent parameters, and the following linear relationship was developed with a coefficient of determination of 0.865 to predict the permeability.

$$
\begin{aligned}
& \mathrm{k}=2.99 \times 10^{-10} \text { Fracture }(x)+ \\
& +2.82 \times 10^{-10}(\alpha)+1.69 \times 10^{-10}
\end{aligned}
$$

In this regard, fracture (x) and $\alpha$ are number of fractures and fracture orientation respectively.

In Equation 2, the coefficient of a fracture's number and the orientation of the fractures is almost the same, which means these two parameters control permeability with an equal weight. 


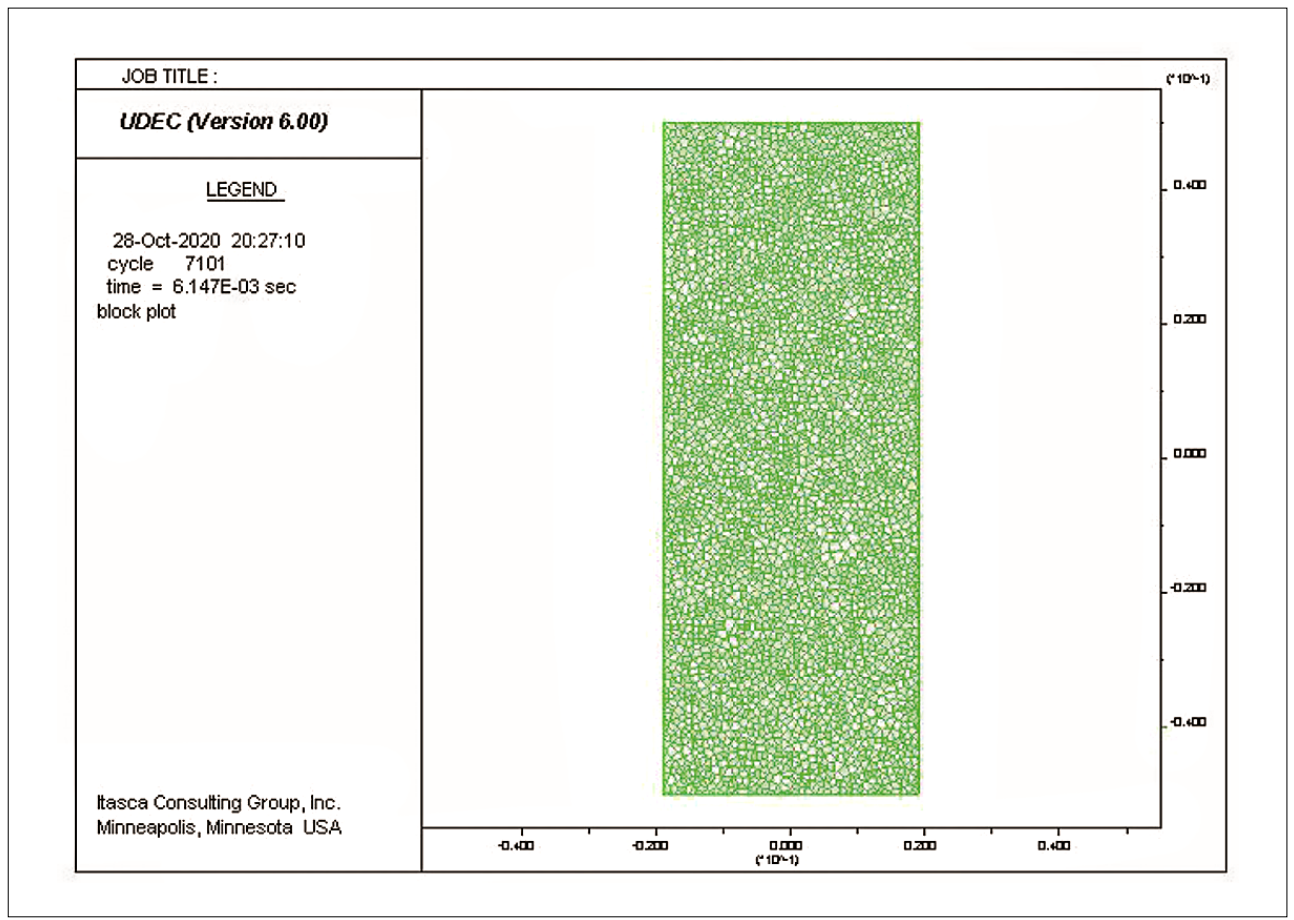

Figure 12: Model geometry with Voronoi elements

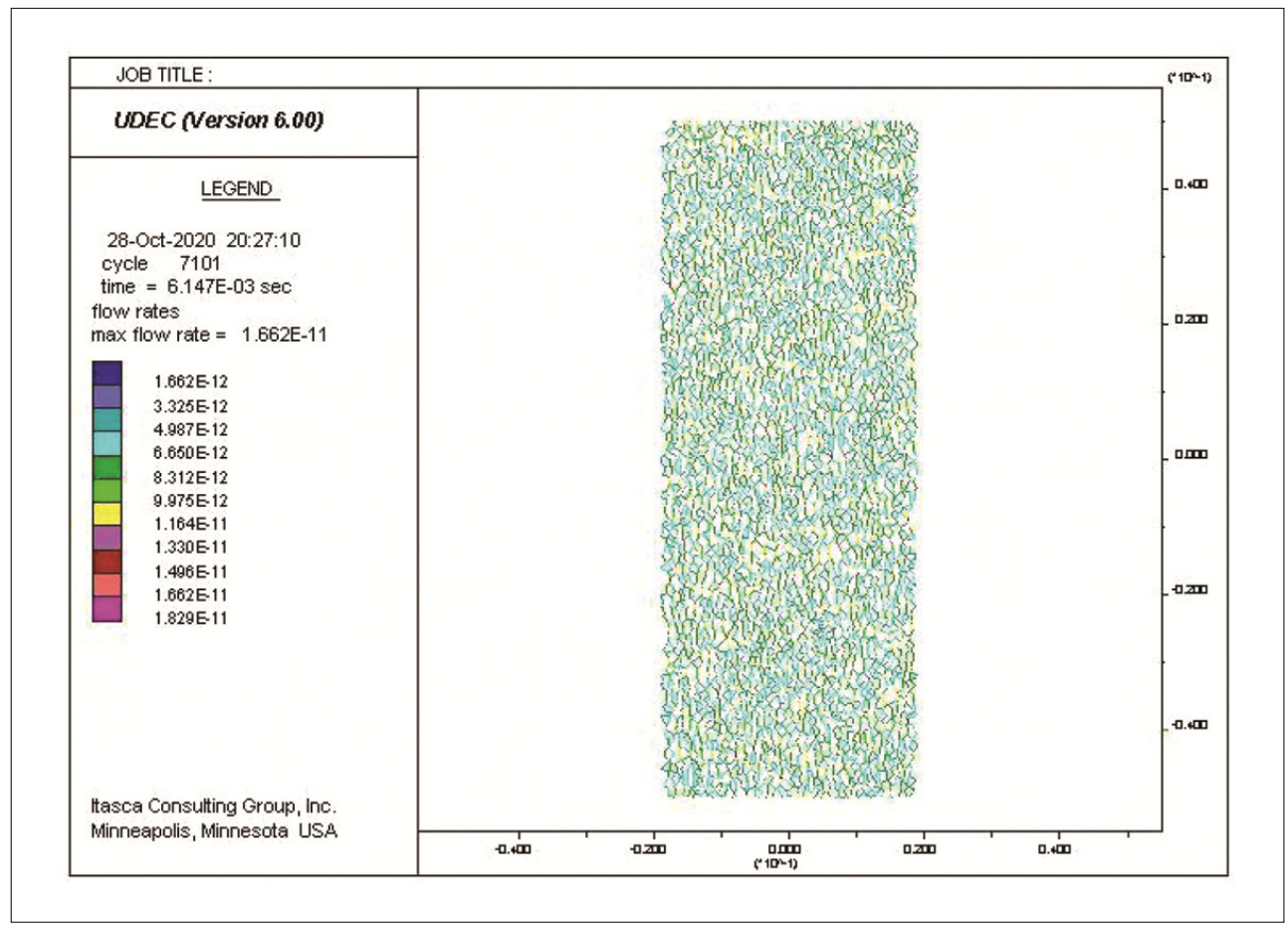

Figure 13: Flow rate contour along the model

\section{Numerical study of the effect of fracture geometry on permeability}

Distinct element method and UDEC software were used for simulation. First, a model's geometry along with the Voronoi elements was generated Figure 12. Then, the lateral boundaries were considered impermeable and the hydraulic gradient was applied perpendicu- lar to the model. After solving the model hydraulically, the total flow rate at the end of the model was investigated and permeability was calculated based on it. The hydraulic parameters of the Voronoi elements, such as the apertures, were selected in such a way as to establish a suitable correlation between the permeability obtained from the numerical method and the laboratory method. Flow rate contour for fracture-free samples is shown in 
Table 2: Comparison of permeability based on laboratory and numerical methods

\begin{tabular}{|c|c|c|c|c|c|c|c|c|c|c|c|}
\hline \multicolumn{4}{|c|}{ Fracture with an angle of $0^{\circ}$} & \multicolumn{4}{|c|}{ Fracture with an angle of $15^{\circ}$} & \multicolumn{4}{|c|}{ Fracture with an angle of $30^{\circ}$} \\
\hline \multirow{2}{*}{ NO } & \multicolumn{3}{|c|}{ Permeability $\mathrm{m} / \mathrm{sec}$} & \multirow{2}{*}{ NO } & \multicolumn{3}{|c|}{ Permeability $\mathrm{m} / \mathrm{sec}$} & \multirow{2}{*}{ NO } & \multicolumn{3}{|c|}{ Permeability $\mathrm{m} / \mathrm{sec}$} \\
\hline & Lab & Numerical & Error\% & & Lab & Numerical & Error\% & & Lab & Numerical & Error\% \\
\hline 1 & $7.9610^{-10}$ & $8.7610^{-10}$ & 10 & 1 & $8.5510^{-10}$ & $9.5810^{-10}$ & 12 & 1 & $9.510^{-10}$ & $1.0510^{-9}$ & 10 \\
\hline 2 & $9.810^{-10}$ & $1.110^{-9}$ & 12 & 2 & $1.110^{-9}$ & $1.2510^{-9}$ & 14 & 2 & $1.2710^{-9}$ & $1.410^{-9}$ & 10 \\
\hline 3 & $1.2210^{-9}$ & $1.3710^{-9}$ & 12 & 3 & $1.3510^{-9}$ & $1.5510^{-9}$ & 15 & 3 & $1.610^{-9}$ & $1.8110^{-9}$ & 13 \\
\hline 4 & $1.3510^{-9}$ & $1.4910^{-9}$ & 10 & 4 & $1.5110^{-9}$ & $1.6810^{-9}$ & 11 & 4 & $1.9610^{-9}$ & $2.1810^{-9}$ & 11 \\
\hline \multicolumn{4}{|c|}{ Fracture at an angle of $45^{\circ}$} & \multirow{4}{*}{ NO } & \multirow{2}{*}{\multicolumn{7}{|c|}{ Fracture with an angle of $60^{\circ}$}} \\
\hline $\mathrm{NO}$ & Lab & Numerical & Error & & & & & & & & \\
\hline \multirow{2}{*}{1} & \multirow{2}{*}{$1.0910^{-9}$} & \multirow{2}{*}{$1.2110^{-9}$} & \multirow{2}{*}{11} & & \multicolumn{7}{|c|}{ Permeability $\mathrm{m} / \mathrm{sec}$} \\
\hline & & & & & Lab & \multicolumn{2}{|l|}{ Numerical } & \multicolumn{4}{|c|}{ Error } \\
\hline 2 & $1.5610^{-9}$ & $1.7310^{-9}$ & 11 & 1 & $1.510^{-9}$ & \multicolumn{2}{|l|}{$1.710^{-9}$} & \multicolumn{4}{|l|}{13} \\
\hline 3 & $2.1410^{-9}$ & $2.4010^{-9}$ & 12 & 2 & $2.2310^{-9}$ & \multicolumn{2}{|l|}{$2.4810^{-9}$} & \multicolumn{4}{|l|}{11} \\
\hline
\end{tabular}

Figure 13. After correlating the numerical model with the laboratory results, fractures were created with the desired orientation and spacing in the model and the amount of permeability was calculated based on the total flow rates obtained at the end of the model. The aperture parameter in all simulations is constant. The results showed that the amount of calculated permeability from the numerical method with a $10-15 \%$ error rate is in good agreement with the permeability obtained from the laboratory method. The permeability and the relevant error are shown in Table 2.

\section{Results and discussions}

The results showed (see Figure 14) that by increasing the number of fractures, or in other words, reducing the spacing, has a significant effect on permeability, especially for fractures with a larger steep angle. The greatest impact of the orientation and spacing on permeability are related to samples with 2 fractures of 60 degrees or a spacing of $12 \mathrm{~mm}$. On the other hand, the smallest impact is associated with the samples with 1 fracture or a spacing greater than $50 \mathrm{~mm}$. In fact, with an increasing fracture orientation, the amount of fluid flow inside the fractures increases locally, and reducing the spacing will cause the fractures to be more affected by each other and will support the transfer of more flow. Therefore, the effect of both orientation and spacing parameters lead to more current transfer. The number of fractures for fractures with orientation greater than 30 degree increased the permeability rate significantly due to the difference in hydraulic gradient. This difference in the permeability

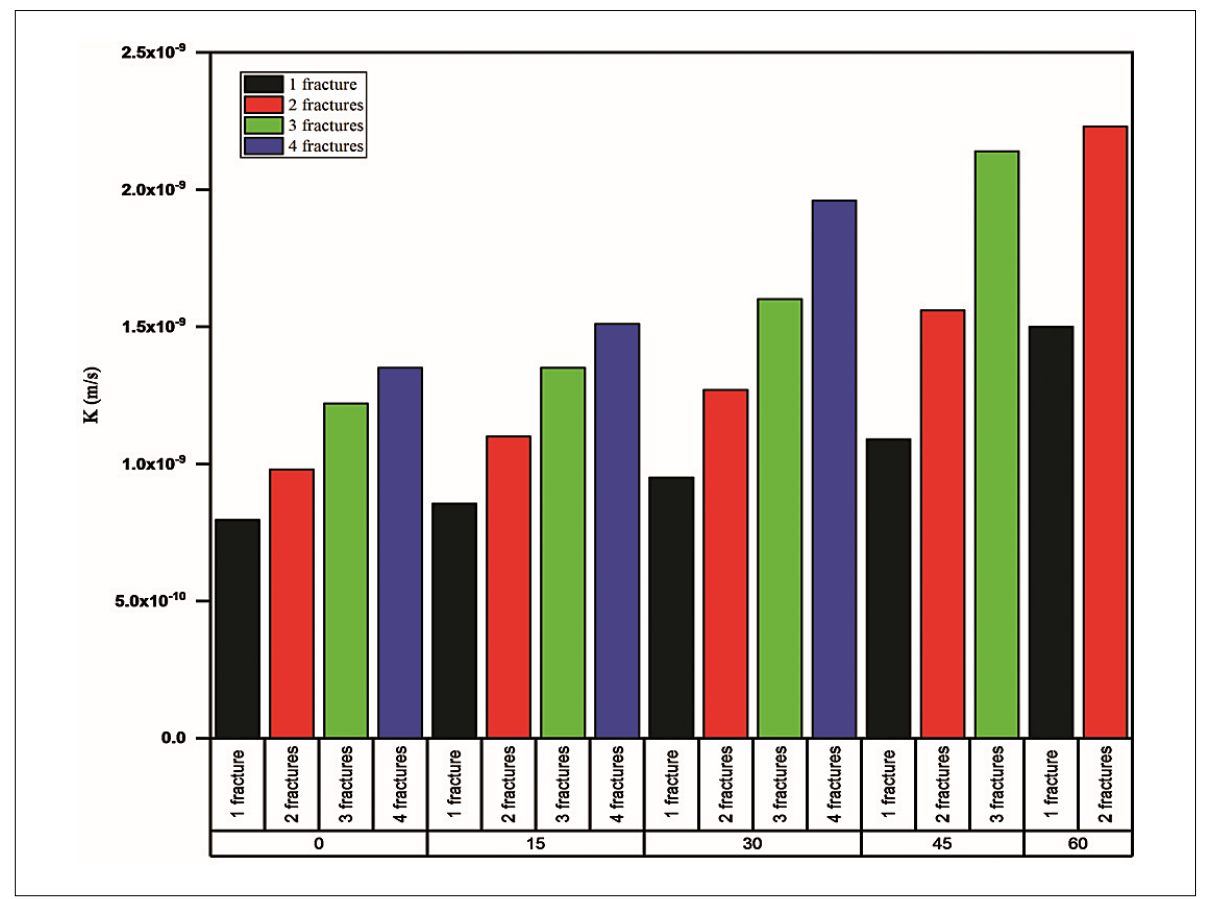

Figure 14: Permeability changes associated with the orientation and spacing of fractures 
between the laboratory scale and numerical modelling can be due to the fact that modelling is considered twodimensional, while in the laboratory scale, the samples are three-dimensional. The second reason could also be the amount of aperture considered in the modelling because the exact value for calculating the aperture was not measured on a laboratory scale.

\section{Conclusion}

The result of physical and mechanical parameters' studies showed that fibrous fiber sample can be a suitable sample to evaluate the impact of the geometry of fractures on permeability. This due to high flexibility, elastic-plastic behavior, low water absorption, and low permeability of fibrous fiber sample. The fracture orientation and spacing studies on fibrous samples showed that permeability was raised exponentially by increasing orientation and decreasing spacing. This increase is greater for fractures with orientation of more than 30 degrees. Also, the effect of spacing on the permeability of fractures with orientation greater than 30 degrees is more significant due to the increase in the flow within the fractures and consequently the greater effect of the flow of discontinuities. The relationship between permeability and the number of fractures is linear, but for fractures with 0 and 15 degree orientation, the permeability rate decreases with an increase in fracture frequency. This trend seems to occur for other orientations with an increasing number of fractures. Changes in permeability are more noticeable with fracture frequency for fractures with an orientation greater than 30 degrees. In the linear equation of permeability with fracture number and fracture orientation parameters, the coefficient of fracture number and fracture orientation is the same. The amount of permeability calculated by using the numerical method of the distinct element and UDEC software showed an error of about $10-15 \%$. This is a good correlation between the permeability calculated by the numerical method and permeability measured in the laboratory method for fractures with different geometries. The error rate is due to the two-dimensional consideration of the model and the aperture parameter assigned to the modelling fracture geometry. The results of this research are useful in the field of Enhanced Oil Recovery (EOR), in which a tight formation reservoir contains low porosity and permeability and the fracture orientation, spacing and aperture play a key role in oil production. However, further studies will be needed, especially for rock materials to make the results more natural.

\section{References}

Arianfar, A., Ramezanzadeh, A. (2020): Numerical study of limestone permeability changes in terms of effective confining stress, case study: South pars reservoir limestone. Special Topic and Reviews in Porous Media, 11, 435-452. DOI: 10.1615/SpecialTopicsRevPorousMedia.2020032297
Bisdom, K., Bertotti, G., Bezerra, F.H. (2017): Inter-well scale natural fracture geometry and permeability variations in low deformation carbonate rocks. Structural Geology, 97, 23-36. DOI:10.1016/j.jsg.2017.02.011

Bisdom, K., Bertotti, G., Nick, H.M. (2016): The impact of in-situ stress and outcrop-based fracture geometry on hydraulic aperture and upscaled permeability in fractured reservoirs. Tectonophysics, 690, 63-75. DOI:10.1016/j. tecto.2016.04.006

Briggs, S., Karney, B.W., Sleep, B.E. (2016): Numerical modeling of the effects of roughness on flow and eddy formation in fractures. Rock Mechanics and Geotechnical Engineering, 9, 1-11. DOI:10.1016/j.jrmge.2016.08.004

Crandall, D., Bromhal, G., Karpyn, Z.T. (2010): Numerical simulations examining the relationship between wallroughness and fluid flow in rock fractures. Rock Mechanics and Mining Sciences, 47, 784-796. DOI:10.1016/j. ijrmms.2010.03.015

Chen, Y., Lian, H., Liang, W., Yang, J., Nguyen, V. P., Bordas, S.P.A. (2019): The influence of fracture geometry variation on non-Darcy flow infractures under confining stresses. Rock Mechanics and Mining Sciences, 113, 59-71. DOI:10.1016/j.ijrmms.2018.11.017

Fheed, A., Kłodowski, K., Krzyżak, A. (2020): Fracture orientation and fluid flow direction recognition in carbonates using diffusion-weighted, nuclear magnetic resonance imaging: an example from Permian. Applied Geophysics, 174, 1-32. DOI:10.1016/j.jappgeo.2020.103964

Gong, J., Rossen, W.R. (2018): Characteristic fracture spacing in primary and secondary recovery for naturally fractured reservoirs. Fuel, 223, 470-485. DOI: https://doi. org/10.1016/j.fuel.2018.02.046

Lang, P.S., Paluszny, A., Nejati, M., Zimmerman, R.W. (2018): Relationship Between the Orientation of Maximum Permeability and Intermediate Principal Stress in Fractured Rocks, Water Resources Research, 54, 8734-8755. DOI:10.1029/2018WR023189

Latham, J.P., Xiang, J., Belayneh, M., Nick, H.M., Tsang, C.F., Blunt, M.J. (2013): Modelling stress-dependent permeability in fractured rock including effects of propagating and bending fractures. Rock Mechanics and Mining Sciences, 57,100-112. DOI: https://doi.org/10.1016/j. ijrmms.2012.08.002

Li, W., Frash, L.P., Welch, N.J., Carey, J.W., Meng, M., Wigand, M. (2021): Stress-dependent fracture permeability measurements and implications for shale gas production. Fuel, 290, 1-16. DOI: https://doi.org/10.1016/j. fuel.2020.119984

Rezaei Niya, S.M., Selvadurai, A.P.S. (2019): Correlation of joint roughness coeficient and permeability of a fracture. Rock Mechanics and Mining Sciences, 113, 150-162. DOI: https://doi.org/10.1016/j.ijrmms.2018.12.008

Shiri, Y., Hassani, H. (2021): Two-component fluid front tracking in fault zone and discontinuity with permeability heterogeneity. The Mining Geological Petroleum Bulletin, 36, 19-30. DOI: https://doi.org/10.17794/rgn.2021.3.2

Tsang, Y.W. (1984): The Effect of Tortuosity on Fluid Flow Through a Single Fracture. Water Recourses, 20, 12091215. DOI: https://doi.org/10.1029/WR020i009p01209 
Wang, Sh., Elsworth, D., Liu, J. (2011): Permeability evolution in fractured coal: The roles of fracture geometry and water-content. Coal Geology, 87, 13-25. DOI: https://doi. org/10.1016/j.coal.2011.04.009

Wang, L., Yu, W. (2019): Mechanistic simulation study of gas Puff and Huff process for Bakken tight oil fractured reservoir. Fuel, 239, 1179-1193. DOI: https://doi.org/10.1016/j. fuel.2018.11.119

Yao, C., Jiang, Q.H., Shao, J.F. (2015): A Numerical Analysis of Permeability Evolution in Rocks with Multiple Fractures. Transport in Porous Media, 108, 289-311. DOI: https://doi.org/10.1007/s11242-015-0476-y

Yu, P., Liu, Y., Wang, J., Kong, Ch., Gu, W., Xue, L., Cheng, Z., Jiang. L. (2020): A new fracture permeability model: Influence of surrounding rocks and matrix pressure. Journal of Petroleum Science and Engineering, 193, 1-21. DOI: https://doi.org/10.1016/j.petrol.2020.107320

Zhang, T., He, X., Liu, Y., Zhao, Y., Yang, K., Yu, X. (2020): Experimental study on permeability response in fractured rock to the effect of hydro-mechanical coupling, fracture geometry, and component content. Natural Hazards, 105, 1439-1451. DOI: 10.1007/s11069-020-04361-6

Zheng, J., Wang, X., Lü, Q., Liu, J., Guo, J., Liu, T., Deng, J. (2019): A Contribution to Relationship Between Volumetric Joint Count ( $\mathrm{J}$ v) and Rock Quality Designation (RQD) in Three-Dimensional (3-D) Space. Rock Mechanics and Rock Engineering, 53, 1485-1494. DOI:10.1007/s00603019-01986-3

Zheng, J., Wang, X., Lü, Q., Sun, H., Guo, J. (2020): A new determination method for the permeability tensor of fractured rock masses. Hydrology, 585, 1-13. DOI: https://doi. org/10.1016/j.jhydrol.2020.124811

Zheng, J., Yang, X., Lü, Q., Zhao, Y., Deng, J., Ding, Z. (2018): A new perspective for the directivity of Rock Quality Designation (RQD) and an anisotropy index of jointing degree for rock masses. Engineering Geology, 240, 81-94. DOI: https://doi.org/10.1016/j.enggeo.2018.04.013

Zimmerman, R.W. (1996): Bodvarsson GS. Hydraulic conductivity of rock fractures. Transport in Porous Media, 23, 1-30. DOI: https://doi.org/10.1007/BF00145263

\section{SAŽETAK}

\section{Procjena utjecaja geometrije pukotina na propusnost, primjer laboratorijskoga ispitivanja i numeričkoga modeliranja}

Geometrija pukotina uglavnom obuhvaća orijentaciju, razmak i promjer, kao varijable koje određuju propusnost stijena. Studije koje se bave izučavanjem geometrije pukotina na laboratorijskim uzorcima imaju preduvjet odabira prikladnih uzoraka za ocjenu fizičkih i mehaničkih svojstava. Stoga je ovdje odabrano vlakno s malom apsorpcijom vode i propusnošću te sa svojstvima nekrtosti, odnosno savitljivosti. Ispitane su 1, 2, 3 i 4 pukotine s razmacima većim od $50 \mathrm{~mm}$, od 50 $\mathrm{mm}$, od 25 i od $15 \mathrm{~mm}$ te orijentacijama od o, 15, 30, 45 i 6o stupnjeva od vodoravne ravnine. Pukotine nisu bile u dodiru s površinom uzorka. Propusnost je rasla eksponencijalno, prateći porast kuta orijentacije i smanjivanje razmaka među pukotinama. To je najbolje opaženo s pukotinama pod kutom većim od 30 stupnjeva. Propusnost dobivena laboratorijski uspoređena je s rezultatima izmjerenim metodom konačnih elemenata i programom UDEC. Dobivena je pogrješka od 10 do $15 \%$ čime je dokazano dobro podudaranje laboratorijskih i numeričkih rezultata.

\section{Ključne riječi:}

propusnost, geometrija pukotina, vlakno, konačni elementi, program UDEC

\section{Author's contribution}

Mohammad Faez (Ph.D student of mining Engineering): provided the sample for tests, conducted the tests and managed the entire manuscript. Ahmad Ramezanzadeh (Associate Professor; Faculty of Mining Eng., Petroleum and Geophysics): developed the device and modelling, Reza Ghavami-Riabi (Associate Professor; Faculty of Mining Eng., Petroleum and Geophysics): presented the constructing comments and evaluated the whole manuscript. Behzad Tokhmechi (Associate Professor; Faculty of Mining Eng., Petroleum and Geophysics): proposed the idea and the analysis of the experimental results. 